\title{
Addis Birhan project: Working with boys and men to address young girls' social vulnerability
}

Annabel Erulkar

Population Council

Louis Apicella

Population Council

Abebaw Ferede

Population Council

Follow this and additional works at: https://knowledgecommons.popcouncil.org/departments_sbsr-pgy

Part of the Demography, Population, and Ecology Commons, Family, Life Course, and Society

Commons, Gender and Sexuality Commons, and the International Public Health Commons

How does access to this work benefit you? Let us know!

\section{Recommended Citation}

Erulkar, Annabel, Louis Apicella, and Abebaw Ferede. 2011. "Addis Birhan project: Working with boys and men to address young girls' social vulnerability," Promoting Healthy, Safe, and Productive Transitions to Adulthood Brief no. 6. New York: Population Council. 


\section{Addis Birhan project: Working with boys and men to address young girls' social vulnerability}

\section{Prepared by Annabel Erulkar, Louis Apicella, Abebaw Ferede}

$\mathrm{M}$ en have traditionally been excluded from initiatives related to reproductive health, family planning, parenthood, and sexuality. Although HIV programs frequently recognize the role of men's risk taking behavior in transmission of HIV, little is known about men's sexual and reproductive health. In Ethiopia, the Ethiopia Ministry of Youth and Sports, the Amhara Regional Bureau of Youth and Sports (ARBOYS), and the Population Council have been implementing programs for vulnerable girls, including married adolescents. As programs for married girls became increasingly popular and widely known, demand for support programs arose from their husbands.

As a result, qualitative, in-depth interviews were undertaken among adolescents, men, and women in the Amhara Region in Ethiopia, exploring the roles of men and women, risk-taking behavior, and patterns of HIV and reproductive health vulnerability. Findings of the study were used to guide development of a program for Ethiopian men in periurban areas, as well as men who are rural-urban migrants.

\section{Addis Birhan for rural men in Ethiopia}

Addis Birhan (Amharic for "new light") is a program of the Regional Bureaus of Youth and Sports in Amhara and Tigray and the Population Council. The program targets married men in periurban and rural areas in northern Ethiopia. Trained male mentors mobilize groups of married men and meet on a weekly basis in community spaces. Mentors range in age from 25 to 40 and have at least six years of education. Groups comprise roughly 25 to 30 men who are typically members of the same gott (village).

Based on existing curricula from Population Council India, Promundo, and EngenderHealth, the Population Council Ethiopia tailored a curriculum for rural Ethiopian men. The 30-hour curriculum includes modules on gender, relationships, caring for children and

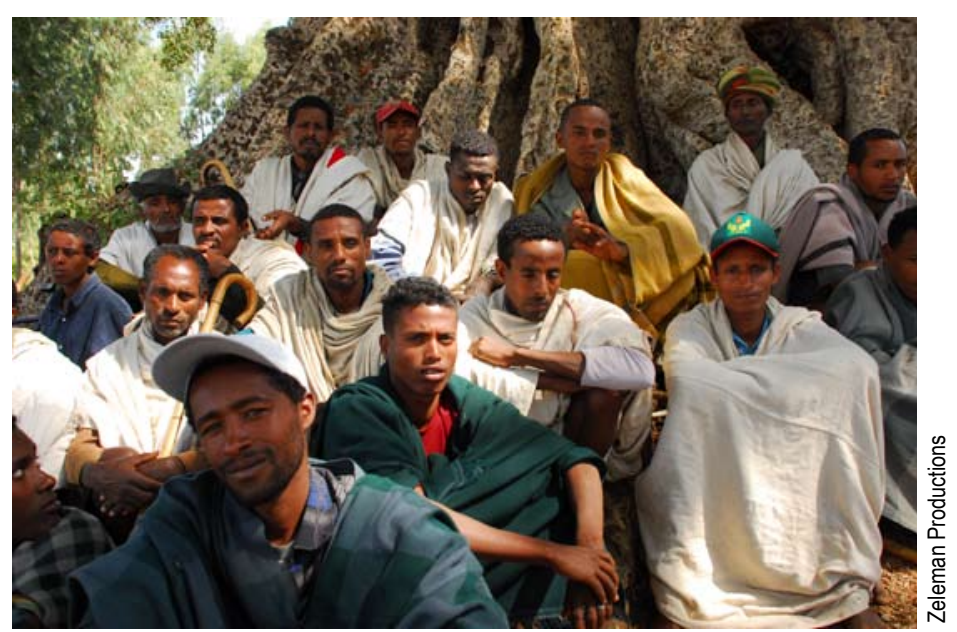

families, drugs and alcohol, HIV and AIDS, sexual and reproductive health (SRH), and violence. The pedagogy is not simply a transfer of information; instead it promotes dialogue, self-exploration, and expression of one's feelings, in a nonjudgmental and safe environment. Because the program targets men with very low levels of education, the curriculum includes many pictures of contextually relevant situations as teaching aids. Typically, groups take three to four months to complete the curriculum.

Engaging large numbers of rural men The program has been implemented since October 2008, under the leadership of one hundred mentors from the project communities. More than 51,000 people have participated in the program, nearly two-thirds of whom have never been to school. The majority are aged 20-39, with an average age of 36 . 


\begin{tabular}{|llc|}
\hline $\begin{array}{l}\text { Table } 1 \text { Characteristics of Addis Birhan members, October } \\
2008 \text { to October } 2010(\mathrm{n}=51,186)\end{array}$ & Percent \\
\hline Age category & $<20$ & 2.0 \\
& 20 to 29 & 30.1 \\
& 30 to 39 & 32.3 \\
40 to 49 & 22.0 \\
$50+$ & 13.6 \\
Years of schooling & None & 63.8 \\
& 1 to 4 years & 24.2 \\
& 5 to 8 years & 8.8 \\
$9+$ years & 3.3 \\
\hline
\end{tabular}

Both qualitative and quantitative data have been collected by the Population Council over the course of the project. Through qualitative research, participants and their families have described positive changes resulting from participation, such as increased communication among couples and dialogue that is two-way, rather than directive. Men report that they return from the group meetings and share what they have learned with their wives and children, effectively opening up dialogue within the home. Spouses have noted that men have started to change the way they think about the distribution of labor in the home; many men now undertake traditionally female roles, such as fetching water or assisting with cooking and child care:

Now I want to quit drinking and I have started to fetch water and prepare firewood when my wife is at the market. I want to help my wife at home, and she is happy about it.

\section{- Married male farmer, age 40, 3 children}

Previously, he was not helping me in the home, but now he even weaves cotton for me.

$$
\text { -Wife of male participant, age 22, } 1 \text { child }
$$

Many members report that they have changed risky behavior, such as drinking, as well as their perceptions of gender norms:

Before, I used to spend a lot of time drinking alcohol, but now I decided to limit the amount I drink...I used to visit sex workers before. Now I do not do that. This education has helped me.

\section{-Married farmer, age 27, 1 child}

For instance if a man comes and asks for my child in marriage, I will refuse, because of the education I got from this program. Now I am leading my life with a plan. I respect equality [between the sexes]. I used to simply watch my wife when she was breast feeding and cooking wot at the same time, and I did not care whether the wot spilled or not... but now I am changed.
Measuring changes associated with the program Population Council researchers are measuring changes associated with the Addis Birhan program related to reproductive health knowledge, gender attitudes, spousal communication and support, and domestic violence, among others. In mid-2008, a baseline survey was undertaken among husbands and married adolescent girls in six districts in Amhara Region. A midterm survey was conducted in June 2010 during which 545 husbands aged 15 to 49 in the intervention site participated. ${ }^{1}$ An endline survey will be undertaken at the end of 2011, allowing researchers to measure changes over the life of the project, using the comparison site to control for changes that would have happened regardless of the project.

At the time of the midterm evaluation, 11 percent of the men in the intervention area had participated in the Addis Birhan program $(n=60)$. Within intervention areas, participants and nonparticipants had comparable demographic characteristics. On average, participants were aged 29 and nonparticipants were 27 ; while 48 percent of participants had never been to school, 43 percent of nonparticipants had never attended.

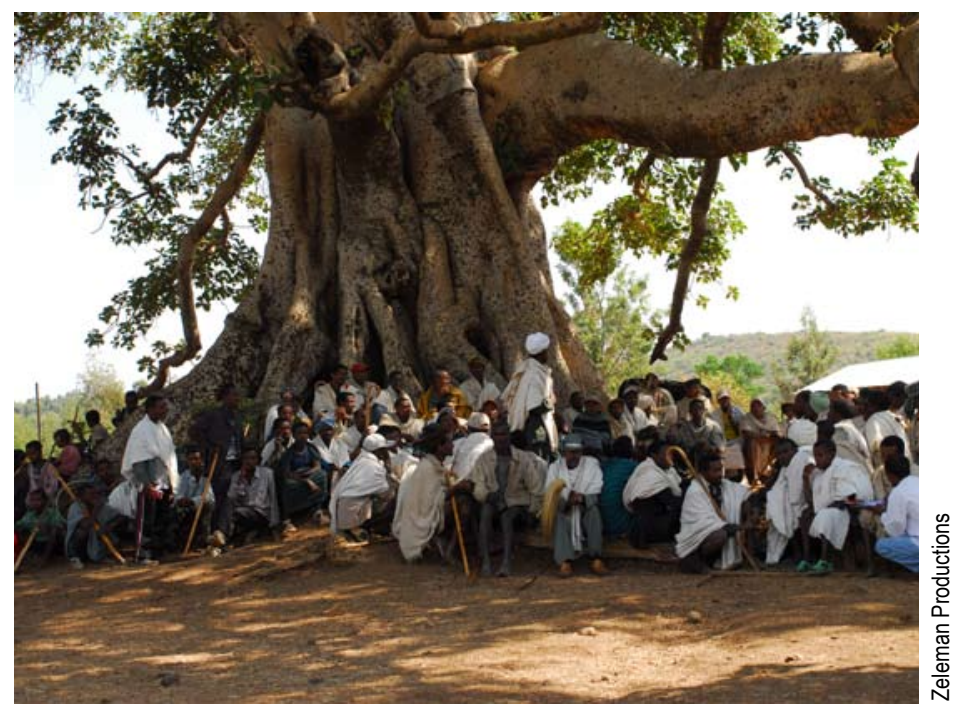

Differences between Addis Birhan participants and nonparticipants in the intervention sites were assessed in terms of gender attitudes, spousal communication, and decisionmaking and spousal support. Husbands participating in the program were more likely than nonparticipants to hold gender-equitable attitudes and significantly less likely to be accepting of domestic violence. When asked about spousal communication in the previous three months and family decisionmaking, a higher percentage of participants had discussed topics or engaged in joint decisionmaking with their spouses, compared with nonparticipants. Moreover, Addis Birhan participants discussed significantly more topics with their spouses and engaged in joint decisionmaking on significantly more issues, compared with their counterparts who had not participated in the program (see Table 2). 
Table 2 Spousal communication, household decisionmaking, and familial support, among husband participants and nonparticipants Addis Birhan program, June 2010

Participants in Addis Birhan $(n=60) \quad$ Nonparticipants $(n=485)$

\section{Discussed topic with spouse in past three months}

Plans for the future

Health issues in the family

Number of children to have

Whether to use family planning

HIVIAIDS

Where to give birth

Whether to use condoms

Mean number of topics discussed with spouse (0 to 7)

Husband reports making joint decision on issues with wife:

Whether to marry children off

Children's health care

How to use land

How to spend money

Whether to have sex

Whether children go to school
$96.7^{*}$

$96.7^{\star}$

76.7

76.7

71.7

50.8

15.3

$4.8^{*}$

93.3

93.3

$81.0^{\text {** }}$

80.0

78.9

66.7

\section{4. $9^{\star}$}

$78.3^{* *}$

$75.0^{* * *}$

63.3

15.0

1.7

7.0
88.4

89.0

67.1

70.7

65.6

44.1

9.9

\section{2}

85.7

85.5

64.8

75.2

68.3

63.2

\section{4}

58.5

47.8

54.1

19.4

7.3

3.7

Chi-square used to test differences between nonexposed versus exposed. ${ }^{*} p<0.05 ;{ }^{* *} p<0.01 ;{ }^{* * *} p<0.001$.

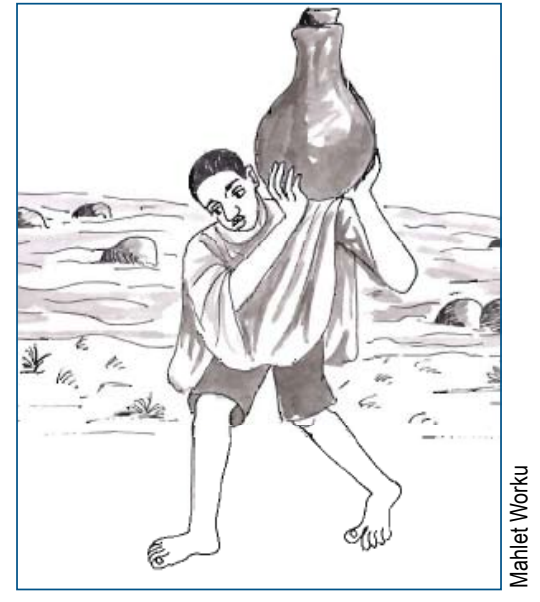

Participants were significantly more likely than nonparticipants to have assisted with domestic work (78 percent of participants;

59 percent of nonparticipants) and significantly more likely to have fetched water in the past three months ( 75 percent of participants; 48 percent of nonparticipants). A lower percentage of participants reported being angry with their spouses and being violent with their spouses, compared with nonparticipants. More participants admitted to being unfaithful, however, though the difference between groups was not significant.

Future directions for Addis Birhan

Midterm results demonstrate that the program is beginning to have an effect on the targeted group of married men who have been exposed to it. Based on promising results from the midterm survey, Addis Birhan is expanding and intensifying efforts in project woredas (districts); additional mentors are being recruited and trained to reach a larger proportion of eligible men. The program is also currently expanding to include groups for unmarried boys.

Donor

USAID/PEPFAR

Partner Institutions

Amhara Regional Bureau of Women, Children and Youth Affairs 


\section{QP Population Council}

The Population Council changes the way the world thinks about critical health and development issues. We seek to understand the causes and consequences of gender inequality and the disparities in opportunity that arise during adolescence. We provide the evidence for better on-theground programs and policies that ensure successful and productive transitions to adulthood in developing countries. www.popcouncil.org

๑) 2011 The Population Council, Inc.

4 - Visit www.popcouncil.org/publications/serialsbriefs/TABriefs.asp for all briefs in the Promoting healthy, safe, and productive transitions to adulthood series. 